\title{
Analisis Pengaruh Penggunaan VTP Pruning pada Jaringan VLAN
}

\section{The Analysis of The Using Effect of VTP Pruning on The VLAN Network}

\author{
Muhammad Giri Sakti ${ }^{1, *}$, Kukuh Nugroho ${ }^{2}$, Jafaruddin Gusti Amri Ginting ${ }^{3}$ \\ 1,2,3 Jurusan S1 Teknik Telekomunikasi, Fakultas Teknik Telekomunikasi dan Elektro, \\ Institut Teknologi Telkom Purwokerto \\ Jl D.I Pandjaitan no. 128, Purwokerto 53147 \\ 1,*Penulis Korespondensi: 18101225@ittelkom-pwt.ac.id, \\ ${ }^{2}$ kukuh@ittelkom-pwt.ac.id, 3jafaruddin@ittelkom-pwt.ac.id
}

Received on 08-06-2020, accepted on 20-10-2020, published on 30-12-2020

\begin{abstract}
Abstrak
VLAN (Virtual Local Area Network) banyak digunakan dalam jaringan komputer untuk mengatur jaringan sesuai dengan kebutuhan pengguna. Penggunaan VLAN mampu memberikan efisiensi dan efektifitas melalui segmentasi jaringan. Selain itu mampu juga memperbaiki kinerja keamanan suatu jaringan. Komunikasi dalam jaringan VLAN sendiri terdapat 2 jenis yaitu komunikasi antar VLAN yang berbeda disebut inter-VLAN dan komunikasi antar VLAN yang sama disebut Intra-VLAN. Didalam Jaringan VLAN ini terdapat Perangkat Switch yang saling dihubungkan dengan jalur Trunk. Komunikasi yang terjadi antar VLAN-ID yang menggunakan jalur Trunking ini menimbulkan pengaruh kualitas parameter QOS. Solusi untuk mengatasi permasalahan tersebut adalah penggunaan VTP Pruning dalam jaringan VLAN. Dalam Penelitian ini akan meng analisis dari pengaruh penggunaan VTP Pruning pada jaringan VLAN. Parameter QOS yang dijadikan acuan analisis performansi adalah throughput, delay, jitter dan packet loss.Berasarkan hasil penelitian diperoleh rata-rata QOS jaringan VLAN yang menggunakan VTP Pruning lebih baik dibandingkan dengan rata-rata jaringan VLAN yang tidak menggunakan VTP Pruning, sehingga dapat disimpulkan bahwa VTP Pruning memiliki pengaruh yang baik bagi jaringan VLAN.
\end{abstract}

Kata kunci: QOS, Trunk, Virtual Local Area Network (VLAN), VLAN Trunking Protocol (VTP), VTP Pruning.

\section{Abstract}

VLAN (Virtual Local Area Network) is widely used in computer networks to manage user needs. The use of VLANs can provide efficiency and effectiveness through network segmentation. In addition, it can also improve the security performance of a network. There are two types of communication in a VLAN network: communication between different VLANs called inter-VLAN and communication between the same VLAN called Intra-VLAN. In this VLAN network, Switch Devices are interconnected by Trunk lines. Communication between VLAN-IDs that use this Trunking path affects the quality of the QoS parameters. The solution to overcome these problems is the use of VTP Pruning in VLAN networks. This research will analyze the effect of using VTP Pruning on VLAN networks. The QoS parameters used as a reference for performance analysis are throughput, delay, jitter, and packet loss. VTP Pruning has a good effect on VLAN networks.

Keywords: QOS, Trunk, Virtual Local Area Network (VLAN), VLAN Trunking Protocol (VTP), VTP Pruning.

\section{Pendahuluan}

Jaringan Komputer adalah sebuah kumpulan komputer, prinnter, dan peralatan lainnya yang saling terhubung. Informasi dan data lainnya bergerak melalui kabel-kabel sehingga memungkinkan pengguna jaringan komputer dapat saling bertukan dokumen atau data [1].Dalam jaringan komputer terdapat perangkat jaringan, salah satunya adalah Switch. Switch adalah perangkat yang difungsikan untuk 
menghubungkan antar komputer. Dalam Konsep Layer OSI perangkat Switch adalah perangkat yang beroperasi pada layer 2 yaitu layer data link [2]. Dalam proses kerja Switch ini melihat informasi mac address yang berada pada tabel ARP saat melakukan pengiriman informasi.Selain itu port Switch akan digabungkan dalam satu wilayah broadcast yang sama. Apabila ada salah satu komputer yang mengirimkan data secara broadcast, maka data tersebut akan diteruskan kesemua port selain port yang digunakan oleh komputer pengirim untuk mengirimkan data broadcast.Maka untuk memecah wilayah broadcast dalam sebuah perangkat switch muncul sebuah teknologi yang dinamakan VLAN (Virtual Local Area Network). Dengan Menggunakan teknologi VLAN inilah, perangkat Switch akan dipecah menjadi 2 atau beberapa wilayah broadcast yang berbeda.

Dalam Perangkat Switch yang diproduksi oleh CISCO terdapat istilah VTP. VTP (VLAN Trunking Protocol) adalah suatu protocol yang digunakan untuk mendistribusikan informasi VLAN ID yang tersimpan dalam sebuah database VLAN ke switch yang lain secara otomatis. Prinsip kerja yang digunakan oleh VTP ini memakai konsep Client-Server. Nantinya dalam sebuah jaringan Switch ada salah satu switch yang dijadikan sebagai server dan ada yang dijadikan client. Switch yang bertindak sebagai server yang akan bertugas untuk mendistribusikan informasi VLAN ID ke Switch yang lain yang statusnya sebagai client.Dengan menggunakan VTP banyaknya data VLAN ID yang baru dibuat cukup dibuat di salah satu switch yang berposisi sebagai VTP Server dan berapapun banyaknya switch yang lain cukup diaktifkan sebagai VTP Client.

Selain itu dalam Teknologi VTP juga terdapat fasilitas yang dinamakan dengan VTP Pruning. VTP Pruning ini adalah fasilitas yang dapat diaktifkan pada jalur trunk untuk tidak meneruskan data dari wilayah VLAN dengan nomor ID tertentu ke wilayah VLAN yang lain dengan menggunakan jalur trunk [2]. Penggunaan VTP Pruning diprediksi akan berpengaruh kepada Parameter QOS. Dengan menggunakan VTP pruning diharapkan dapat menjadikan kualitas QOS lebih baik dan tepat sasaran dan jaringan secara umum terutama yang menyangkut data Multicast atau Unicast [2]. Penelitian ini menganalisis pengaruh penggunaan VTP Pruning pada jaringan VLAN yang mana diharapkan dapat memberi informasi tentang kemampuan, tingkat kinerja dan pengaruh VTP Pruning di sebuah jaringan VLAN.

\section{KaJian Pustaka}

Jenis-jenis jaringan komputer dan manfaat jaringan komputer jika di bandingkan dengan komputer yang hanya berdiri sendiri (stand-alone) [3]. Dalam Jaringan komputer terdapat perangkat Switch yang kerap digunakan utamanya di jaringan VLAN.Switch dapat mempelajari alamat hardware host tujuan, sehingga informasi bisa langsung dikirim ke host tujuan. Selain itu switch yang cerdas juga dapat mengecek frame yang error dan dapat memblok frame yang error tersebut [4]. Dalam penggunaannya, perangkat switch terbagi menjadi dua jenis yakni unmanaged switch dan managed switch. Kedua perangkat tersebut mempunyai perannya masing - masing[5]. Melalui perangkat Switch dapat dibuat suatu jaringan LAN, Local Area Network (LAN) yang merupakan jaringan milik pribadi di dalam sebuah gedung atau kampus yang berukuran sampai beberapa kilometer dengan tujuan memakai bersama sumber daya dan saling bertukar informasi [6] .

Untuk mengatasi kekurangan yang ada di jaringan LAN maka muncul konsep VLAN (Virtual Local Area Network) . Virtual LAN adalah suatu model jaringan yang tidak terbatas pada lokasi fisik sehingga dapat menciptakan jaringan secara virtual untuk memecah broadcast domain yang diterapkan melalui konfigurasi pada suatu perangkat switch. Virtual LAN (VLAN) terbangun karena adanya konsep subneting dan LAN (Local Area Network). Virtual LAN dapat disebut juga sebagai pengembangan dari LAN [7].

\section{A. VTP (VLAN Trunking Protocol)}

Jalur trunk adalah sebuah point-to-point link antara 1 atau lebih Ethernet switch interfaces dengan device lainnya, seperti router atau switch. Ethernet trunks dapat membawa traffic data dari berbagai VLAN hanya dalam sebuah link [8]. Sebuah VLAN trunk memungkinkan pertukaran data dalam seluruh jaringan. Metode trunk ini menggunakan protokol IEEE 802.1Q untuk saling berkomunikasi pada interface Fast Ehternet dan Gigabit Ethernet.VLAN trunking protocol (VTP) digunakan untuk mengkomunikasikan informasi VLAN antara switch dalam domain VTP yang sama [9]. Fungsi utama VTP yaitu menyederhanakan pekerjaan pengembang jaringan atau administrator dalam pengelolaan dan pembuatan jaringan VLAN yang baru. Pada VTP, ada yang bertindak sebagai server, transparant maupun client 
[10].VLAN Trunking Potocol (VTP) pruning adalah fitur di cisco switch yang bisa diaktifkan pada jalur trunk untuk tidak meneruskan data dari wilayah VLAN dengan nomor ID tertentu ke wilayah VLAN yang lain dengan menggunakan jalur trunk. Dalam operasi normal switch perlu membanjiri frame broadcast, frame multicast atau frame unicast dimana alamat tujuan MAC tidak diketahui untuk semua port-nya. Jika saklar tetangga tidak memiliki port aktiv dalam sumber VLAN, siaran ini tidak perlu dan tidak diinginkan lalu lintas yang berlebihan dapat menimbulkan masalah pada jaringan [9].

\section{Metode Penelitian}

Metodologi penelitian berisi diagram alur penelitian, Topologi simulasi jaringan, Qos (Quality of Service), dan alat yang digunakan dalam rancangan topologi jaringan. Diagram alur penelitian menjelaskan mengenai tahap penelitian. Selanjutnya Topologi Simulasi Jaringan yang menjelaskan mengenai topologi jaringan yang digunakan dalam penelitian sebagai objek pengambilan data untuk proses analisis penelitian. Qos (Quality of Service) membahas mengenai parameter parameter yang digunakan sebagai acuan dalam menilai qualitas jaringan. Dalam proses simulasi juga membutuhkan alat pendukung yang berfungsi untuk menunjang jalannya penelitian. Secara garis besar, penelitian ini ditujukan untuk melakukan simulasi penggunaan VTP Pruning pada jaringan VLAN. Data hasil simulasi akan dianalisis Pengaruhnya terhadap Qos (Quality of service). Penelitian ini dilakukan dengan mengacu pada Gambar 1 berikut :

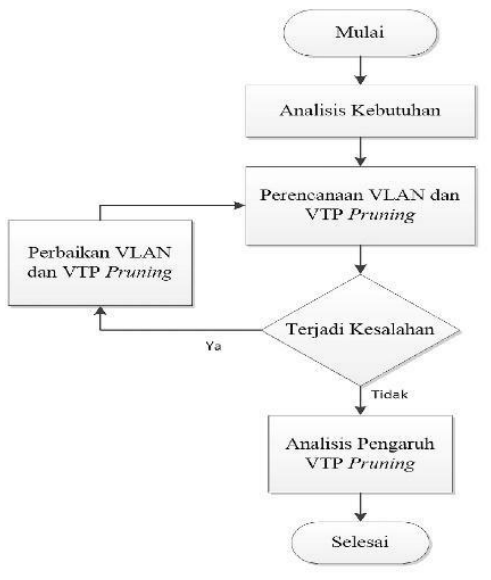

Gambar. 1. Diagram alur penelitian

Topologi jaringan VLAN dan VTP Pruning yang dirancang menggunakan 1 buah topologi yang kemudian dibandingkan hasilnya antara yang menggunakan fitur VTP Pruning dengan yang tidak menggunakan VTP Pruning, sehingga dari situ diharapkan mampu menganalisa pengaruh fitur VTP Pruning terhadap jaringan VLAN. Gambaran topologi yang dirancang menggunakan GNS3 dapat dilihat pada Gambar 3 sebagai topologi jaringan yang dipakai dalam penelitian.

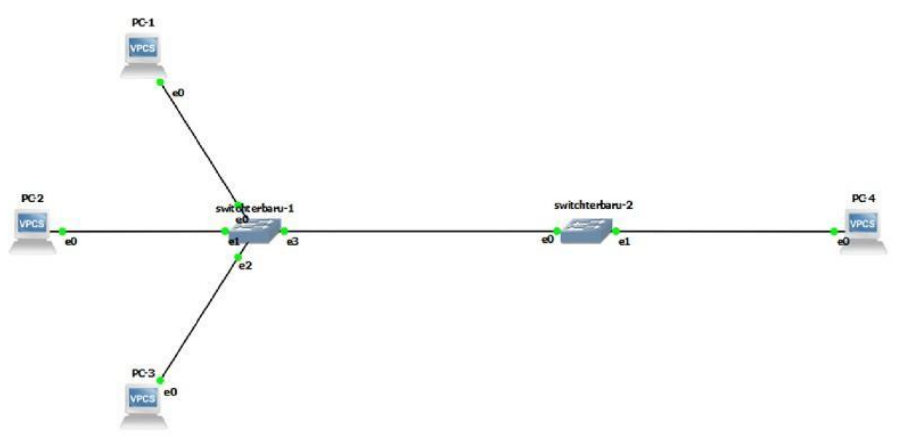

Gambar. 2. Topologi VLAN dan VTP Pruning 
Dari Gambar 3 dapat dilihat bahwa terdapat 2 buah switch saling terhubung. Kemudian switch 1 terhubung dengan 3 buah komputer dimana komputer 1 termasuk VLAN 10, komputer 2 termasuk VLAN 20 dan komputer 3 termasuk VLAN 10. Selanjutnya Switch 2 berada di sisi kanan terbuhung dengan 1 buah komputer yaitu komputer 4 yang termasuk VLAN 20. Jaringan VLAN yang akan diterapkan dianalisis performansinya antara yang menerapkan fitur VTP Pruning dibandingkan dengan jaringan VLAN yang tidak menggunakan fitur VTP Pruning. Dari perbandingan tersebut dapat dianalisis hasilnya bagaimana pengaruh penggunaan fitur VTP pruning dalam sebuah jaringan VLAN yang dilihat disisi parameter QOS nya. Konfigurasi VLAN dan VTP Pruning dari topologi jaringan yang dirancang menggunakan GNS 3 adalah sebagai berikut :

\section{A. Konfigurasi IP Address}

Proses awal dimulai dengan melakukan konfigurasi IP address di setiap perangkat jaringan. Pada topologi, VLAN 10 yang terhubung dengan switch 1 menggunakan IP 192.168.10.1 pada komputer 1 dan IP 192.168.10.3 pada komputer 3 sedangkan pada VLAN 20 yaitu komputer 2 menggunakan IP 192.168.10.2. Disisi kanan Switch 2 terhubung dengan 1 buah Komputer yang mana termasuk VLAN 20 dengan komputer 4 memiliki IP 192.168.10.4 .Koneksi antar switch menggunakan trunk mode dan menggunakan network IP 192.168.10.0.

\section{B. Konfigurasi Virtual Local Area Network (VLAN)}

Topologi jaringan pada Gambar 2 akan dibandingkan antara topologi VLAN yang tidak menggunakan fitur VTP Pruning dengan yang menggunakan fitur VTP Pruning untuk kemudian dibandingkan performansinya melalui acuan parameter QOS. Adapun VLAN yang digunakan dalam topologi jaringan pada Gambar 2 yaitu VLAN 10 dan VLAN 20.

Untuk dapat saling bertukar informasi antar VLAN, setiap client menggunakan port yang terhubung ke switch. Port yang menghubungkan antara client dengan switch menggunakan konfigurasi mode access. Setiap switch akan menerima frame atau paket VLAN ID dari port client kemudian akan mentransmisikan frame atau paket kembali ke VLAN ID yang menjadi tujuan menggunakan port yang menghubungkan antar switch. Setiap switch dapat mentransmisikan frame atau paket dengan lebih dari 1 VLAN ID yang berbeda. Port yang menghubungkan antar switch menggunakan konfigurasi mode trunk.

\section{Konfigurasi VTP Pruning}

Setiap switch saling terhubung sehingga membentuk mode akses trunk. Dalam topologi tersebut, masingmasing Switch terhubung dengan VLAN. Topologi 1 memiliki 2 buah VLAN dan Konsep VLAN memiliki protokol VTP yang membuat data VLAN ID baru cukup dibuat pada salah satu switch yang berposisi sebagai VTP server dan switch yang lain cukup diaktifkan sebagai VTP client. Protocol VTP ini memiliki istilah dalam penggunannya, salah satunya adalah VTP Pruning.

VTP Pruning adalah sebuah fasilitas yang mampu diaktifkan pada jalur trunk untuk tidak meneruskan data dari wilayah VLAN dengan nomor ID tertentu ke wilayah VLAN yang lain dengan menggunakan jalur trunk. Jika suatu PC dalam sebuah VLAN mengirimkan broadcast,multicast atau unicast dan di switch lain tidak terdapat VLAN yang dituju maka hal ini akan membebani jaringan terutama penggunaan bandwidth. Agar penggunaan bandwidth lebih efektif daan tepat sasaran maka perlu kita aktifkan fasilitas VTP Pruning dalam perangkan Switch.yang diaktivkan dengan Konfigurasi VTP Pruning .

\section{Analisis Pengaruh VTP Pruning}

Pada tahapan ini, dilakukan analisis sistem dengan cara membandingkan kinerja jaringan VLAN yang menggunakan VTP Pruning dengan Jaringan VLAN yang tidak menggunakan fitur VTP Pruning. Dari hasil perbandingan tersebut diharapkan mampu mengetahui pengaruh fitur VTP pruning apakah membuat parameter QOS sesuai standar, lebih baik dari standar atau mengurangi QOS jaringan komputer.

\section{QOS (Quality Of Service)}

Quality Of Service (QOS) merupakan metode pengukuran tentang seberapa baik jaringan dan merupakan suatu usaha untuk mendefinisikan karakteristik dan sifat dari suatu service [11].QoS sangat ditentukan oleh 
kualitas jaringan yang digunakan. Terdapat beberapa faktor yang dapat menurunkan nilai QoS, seperti : redaman, distorsi, dan noise [12]. Parameter QoS adalah [12]:

\section{a. Packet Loss}

Merupakan suatu parameter yang menggambarkan suatu kondisi yang menunjukkan jumlah total paket yang hilang, dapat terjadi karena collision dan congestion pada jaringan dan hal ini berpengaruh pada semua aplikasi karena retransmisi akan mengurangi efisiensi jaringan secara keseluruhan meskipun jumlah bandwidth cukup tersedia untuk aplikasi aplikasi tersebut.

Tabel 1. Kategori Packet Loss [13]

\begin{tabular}{|c|c|c|}
\hline Kategori Degredasi & Packet Loss & Indeks \\
\hline Sangat Bagus & $0 \%$ & 4 \\
\hline Bagus & $3 \%$ & 3 \\
\hline Sedang & $15 \%$ & 2 \\
\hline Jelek & $\%$ & 1 \\
\hline
\end{tabular}

\section{b. Delay}

Delay Adalah waktu yang dibutuhkan data untuk menempuh jarak dari asal ke tujuan. Delay dapat dipengaruhi oleh jarak, media fisik, kongesti atau juga waktu proses yang lama.

Tabel 2. Kategori Delay [13]

\begin{tabular}{|c|c|c|}
\hline $\begin{array}{c}\text { Kategori } \\
\text { Latensi }\end{array}$ & Besar Delay & Indeks \\
\hline Sangat Bagus & $<150 \mathrm{~ms}$ & 4 \\
\hline Bagus & $150 \mathrm{~s} / \mathrm{d} 300 \mathrm{~ms}$ & 3 \\
\hline Sedang & $300 \mathrm{~s} / \mathrm{d} 450$ & 2 \\
\hline Jelek & $>450 \mathrm{~ms}$ & 1 \\
\hline
\end{tabular}

Delay dapat dicari dengan membagi antara panjang paket (L, packet length (bit/s)) dibagi dengan link bandwith (R, link bandwith (bit/s)). Pada Tabel 2 diperlihatkan kategori dari latensi dan besar Delay.

\section{c. Throughput}

Yaitu kecepatan (rate) transfer data efektif, yang diukur dalam bps. Throughput merupakan jumlah total kedatangan paket yang sukses yang diamati pada tujuan selama interval waktu tertentu dibagi oleh durasi interval waktu tersebut.

\section{d. Jitter}

Jitter lazimnya disebut variasi delay, berhubungan erat dengan latency, yang menunjukkan banyaknya variasi delay pada taransmisi data di jaringan. Delay antrian pada router dan switch dapat menyebabkan jitter.

Tabel 3. Kategori Jitter [13]

\begin{tabular}{|c|c|c|}
\hline $\begin{array}{c}\text { Kategori } \\
\text { Jitter }\end{array}$ & Jitter & Indeks \\
\hline Sangat Bagus & $0 \mathrm{~ms}$ & 4 \\
\hline Bagus & $0 \mathrm{~ms} \mathrm{~s} / \mathrm{d} 75 \mathrm{~ms}$ & 3 \\
\hline Sedang & $75 \mathrm{~ms} \mathrm{~s} / \mathrm{d} 125 \mathrm{~ms}$ & 2 \\
\hline Jelek & $125 \mathrm{~ms} \mathrm{~s} / \mathrm{d} 225 \mathrm{~ms}$ & 1 \\
\hline
\end{tabular}

\section{Hasil dan Pembahasan}

Pengujian Sistem dilakukan setelah dibuat topologi jaringan untuk melakukan proses simulasi. Setelah simulasi maka barulah dapat dilakukan pengujian sistem dan proses analisis mengenai pengaruh penggunaan VTP Pruning dalam jaringan VLAN dilihat dari parameter acuan yaitu parameter throughput, packet loss, delay dan jitter. Pengiriman paket menggunakan ping sebanyak 100 kali dengan ukuran 1000 
bytes sedangkan protokolnya adalah ICMP dari PC 2 ke PC 4 yang sama sama termasuk kedalam VLAN 20. Disaat yang bersamaan, dilakukan juga ping sebanyak 100 kali dengan ukuran bytes 1000 dari PC 3 ke PC 1 yang kedunya termasuk VLAN 10. Penelitian ini menggunakan 2 skenario, yaitu skenario pertama dengan switch 1 mengaktivkan fitur VTP Pruning dan pengukuran QOS dilakukan pada sisi penerima yaitu PC 4 yang termasuk VLAN 20.

Skenario kedua dilakukan dengan tanpa mengaktivkan fitur VTP Pruning di Switch 1 untuk kemudian dibandingkan hasil parameter QOSnya diantara yang mengaktivkan VTP Pruning dengan yang tidak mengaktivkan fitur VTP Pruning. Pengiriman paket dan proses capture data ini dilakukan sebanyak 10 kali di masing masing skenario percobaan. Denagn demikian dapat diketahui bagaimana pengaruh dari penggunaan VTP Pruning dalam sebuah jaringan VLAN berdasarkan parameter Throughput, Packet Loss, Delay dan Jitter.

\section{A. Throughput}

Throughput adalah salah satu parameter QOS jaringan dalam satuan bps yang merepresentasikan kecepatan (rate) transfer data efektif. Pengukuran throughput ini bertujuan untuk mengetahui performansi jaringan ketika mentransmisikan data secara actual. Throghput dapat diperoleh melalui perhitungan manual dengan cara membagi besar paket dengan waktu delay paket terkirim. Hasil dari proses pengambilan data parameter throughput menggunakan wireshark ditampilkan di Tabel 4.

Tabel 4. Hasil Capture Throughput

\begin{tabular}{|c|c|c|c|c|}
\hline \multirow{2}{*}{$\begin{array}{l}\text { capture } \\
\text { ke }\end{array}$} & \multicolumn{2}{|c|}{$\begin{array}{c}\text { VTP Pruning Non } \\
\text { Aktif }\end{array}$} & \multicolumn{2}{|c|}{ VTP Pruning Aktif } \\
\hline & Paket & Throughput & $\begin{array}{c}\text { Pake } \\
\text { t }\end{array}$ & $\begin{array}{c}\text { Throughpu } \\
\text { t }\end{array}$ \\
\hline 1 & 200 & 2058 & 200 & 2074 \\
\hline 2 & 200 & 2053 & 200 & 2071 \\
\hline 3 & 200 & 2065 & 200 & 2071 \\
\hline 4 & 200 & 1980 & 200 & 2070 \\
\hline 5 & 200 & 2024 & 200 & 2069 \\
\hline 6 & 200 & 2063 & 200 & 2064 \\
\hline 7 & 200 & 2007 & 200 & 2058 \\
\hline 8 & 200 & 2062 & 200 & 2037 \\
\hline 9 & 200 & 2061 & 200 & 2055 \\
\hline 10 & 200 & 2062 & 200 & 2066 \\
\hline \multicolumn{2}{|c|}{ rata-rata throughput } & 2043.5 & & 2063.5 \\
\hline
\end{tabular}

Berdasarkan hasil capture data diatas dapat diketahui bahwa sebagian besar throughput dalam jaringan dengan VTP pruning aktiv nilainya lebih besar jika dibandingkan dengan throughput dalam jaringan yang tidak mengaktivkan VTP pruning. Dalam skenario dilakukan 10 kali pengambilan data dengan ukuran 1000 bytes masing masing ketika VTP pruning aktiv dan ketika tidak aktiv. Ping dalam proses simulasi dilakukan sebanyak 100 kali antar VLAN yang sama yaitu PC 2 ke PC 4 yang merupakan VLAN 20 dan PC 3 ke PC 1 yang merupakan VLAN 10 sebagai bentuk ping tambahan untuk melihat pengaruh VTP pruning. Dalam capture data setelah simulasi dilakukan, terlihat jumlah paket data sebanyak 200.

Hasil capture dapat disimpulkan melalui rata-rata throughput akhir, dimana throughput dengan VTP pruning aktiv lebih besar dibandingkan Tanpa VTP Pruning, sehingga penggunaan VTP Pruning mempunyai pengaruh yang baik terhadap kualitas parameter Throughput. Adapun throughput yang dilihat atau dilakukan proses capture merupakan dari sisi client di PC 4 VLAN 20. Berdasarkan hasil tersebut, 
hasil throughput tertinggi yaitu sebesar 2074 Kbps , pada jaringan yang mengaktivkan6 VTP Pruning dan throughput terendah yaitu sebesar 1980 Kbps pada pada jaringan yang tidak mengaktivkan VTP Pruning.

\section{B. Delay}

Delay adalah waktu tunda dari suatu paket yang diakibatkan oleh proses transmisi dari satu titik ke titik yang lain atau dari pengirim ke penerima. Delay muncul sebagai akibat dari adanya antrian yang panjang ketikan pengiriman paket atau juga bisa di akibatkan pengambilan rute lain saat pengiriman paket untuk menghindarkan kemacetan. Berikut ini dapat dilihat hasil pengambilan data parameter Delay yang ditampilkan dalam Tabel 5.

Tabel 5. Hasil Capture Delay

\begin{tabular}{|c|c|c|c|c|c|c|c|c|c|c|}
\hline \multirow[b]{2}{*}{$\begin{array}{l}\text { captu } \\
\text { re ke }\end{array}$} & \multicolumn{4}{|c|}{ VTP Pruning Non Aktif } & \multirow[b]{2}{*}{$\begin{array}{c}\text { Kate } \\
\text { gori }\end{array}$} & \multicolumn{5}{|c|}{ VTP Pruning Aktif } \\
\hline & $\begin{array}{l}\text { Pa } \\
\text { ket }\end{array}$ & $\begin{array}{l}\text { Total } \\
\text { delay }\end{array}$ & $\begin{array}{l}\text { Rata- } \\
\text { Rata } \\
\text { Delay }\end{array}$ & $\begin{array}{l}\text { Delay } \\
\text { Acuan }\end{array}$ & & $\begin{array}{l}\text { Pac } \\
\text { ket }\end{array}$ & $\begin{array}{l}\text { Total } \\
\text { delay }\end{array}$ & $\begin{array}{l}\text { Rata- } \\
\text { Rata } \\
\text { Delay }\end{array}$ & $\begin{array}{l}\text { Delay } \\
\text { Acuan }\end{array}$ & $\begin{array}{l}\text { Kate } \\
\text { gori }\end{array}$ \\
\hline 1 & $\begin{array}{c}20 \\
0 \\
\end{array}$ & $\begin{array}{c}101.22 \\
8 \\
\end{array}$ & 0.50614 & 506.14 & Jelek & 200 & $\begin{array}{c}100.47 \\
63 \\
\end{array}$ & 0.5023815 & $\begin{array}{c}502.381 \\
5 \\
\end{array}$ & jelek \\
\hline 2 & $\begin{array}{c}20 \\
0\end{array}$ & $\begin{array}{c}101.48 \\
3\end{array}$ & 0.507415 & 507.415 & jelek & 200 & $\begin{array}{c}100.60 \\
3\end{array}$ & 0.503015 & 503.015 & jelek \\
\hline 3 & $\begin{array}{c}20 \\
0 \\
\end{array}$ & $\begin{array}{c}100.90 \\
4 \\
\end{array}$ & 0.50452 & 504.52 & jelek & 200 & $\begin{array}{c}100.58 \\
1 \\
\end{array}$ & 0.502905 & 502.905 & jelek \\
\hline 4 & $\begin{array}{c}20 \\
0\end{array}$ & $\begin{array}{c}105.22 \\
6\end{array}$ & 0.52613 & 526.13 & jelek & 200 & $\begin{array}{c}100.66 \\
67\end{array}$ & 0.5033335 & $\begin{array}{c}503.333 \\
5\end{array}$ & jelek \\
\hline 5 & $\begin{array}{c}20 \\
0\end{array}$ & $\begin{array}{c}102.92 \\
45\end{array}$ & 0.5146225 & $\begin{array}{c}514.622 \\
5 \\
\end{array}$ & jelek & 200 & $\begin{array}{c}100.69 \\
3\end{array}$ & 0.503465 & 503.465 & jelek \\
\hline 6 & $\begin{array}{c}20 \\
0 \\
\end{array}$ & $\begin{array}{c}100.98 \\
77 \\
\end{array}$ & 0.5049385 & $\begin{array}{c}504.938 \\
5 \\
\end{array}$ & jelek & 200 & $\begin{array}{c}100.93 \\
2 \\
\end{array}$ & 0.50466 & 504.66 & jelek \\
\hline 7 & $\begin{array}{c}20 \\
0\end{array}$ & $\begin{array}{c}103.81 \\
4\end{array}$ & 0.51907 & 519.07 & jelek & 200 & $\begin{array}{c}101.24 \\
8\end{array}$ & 0.50624 & 506.24 & jelek \\
\hline 8 & $\begin{array}{c}20 \\
0\end{array}$ & $\begin{array}{c}101.05 \\
9\end{array}$ & 0.505295 & 505.295 & jelek & 200 & $\begin{array}{c}102.26 \\
9\end{array}$ & 0.511345 & 511.345 & jelek \\
\hline 9 & $\begin{array}{c}20 \\
0\end{array}$ & $\begin{array}{c}101.10 \\
1\end{array}$ & 0.505505 & 505.505 & jelek & 200 & $\begin{array}{c}101.36 \\
5\end{array}$ & 0.506825 & 506.825 & jelek \\
\hline 10 & $\begin{array}{c}20 \\
0\end{array}$ & $\begin{array}{c}101.06 \\
5\end{array}$ & 0.505325 & 505.325 & jelek & 200 & $\begin{array}{c}100.86 \\
05\end{array}$ & 0.5043025 & $\begin{array}{c}504.302 \\
5 \\
\end{array}$ & jelek \\
\hline $\begin{array}{r}\text { rata- } \\
\text { del }\end{array}$ & & $\begin{array}{c}101.97 \\
922\end{array}$ & 0.5098961 & $\begin{array}{c}509.896 \\
1\end{array}$ & jelek & & $\begin{array}{c}100.96 \\
945\end{array}$ & $\begin{array}{c}0.5048472 \\
5\end{array}$ & $\begin{array}{c}504.847 \\
25\end{array}$ & jelek \\
\hline
\end{tabular}

Berdasarkan tabel diatas, dapat diketahui hasil rekapitulasi delay dari skenario yang telah dilakukan, yaitu simulasi jaringan yang mengaktivkan VTP Pruning dengan yang tidak mengaktifkan VTP Pruning untuk dibandingkan hasil akhir antara keduanya. Dalam skenario simulasi dilakukan ping 100 kali dengan ukuran bytes sebesar 1000 dan proses pengambilan datanya dilakukan sebanyak 10 kali. Dalam capture data setelah simulasi dilakukan, terlihat jumlah paket data sebanyak 200.Ping dalam proses simulasi antar VLAN yang sama yaitu PC 2 ke PC 4 yang merupakan VLAN 20 dan PC 3 ke PC 1 yang merupakan VLAN 10 sebagai bentuk ping tambahan untuk melihat pengaruh VTP pruning melalui hasil parameter QOSnya.

Hasil capture dapat disimpulkan melalui rata-rata Delay acuan akhir, dimana Delay dengan VTP pruning aktiv lebih lebih kecil nilainya dibandingkan Tanpa VTP Pruning, sehingga penggunaan VTP Pruning mempunyai pengaruh yang baik terhadap kualitas parameter Delay, walaupun kategori nilai keduanya masih termasuk kedalam kategori buruk dalam standar parameter TIPHON. Adapun Delay yang dilihat atau dilakukan proses capture merupakan dari sisi client di PC 4 VLAN 20.

Berdasarkan hasil tersebut, hasil delay tertinggi yaitu sebesar $526.13 \mathrm{~ms}$, pada jaringan tanpa VTP Pruning dan delay terendah yaitu sebesar $502.3815 \mathrm{~ms}$ pada pada jaringan yang mengaktivkan VTP 
Pruning. Dapat disimpulkan nilai keseluruhan delay masih berkisaran $>450 \mathrm{~ms}$, dimana hasil delay ini termasuk dalam kategori buruk dalam standardisasi versi TIPHON.

\section{Jitter}

Jitter adalah variasi delay atau juga bisa disebut sebagai variasi kedatangan paket, diakibatkan oleh variasi-variasi dalam panjang antrian dalam waktu pengolahan data. Nilai Jitter tergantung kepada nilai delay. Berikut ini hasil pengambilan data parameter Jitter yang ditampilkan pada tabel 6.

Tabel 6. Hasil Capture Jitter

\begin{tabular}{|c|c|c|c|c|c|c|c|c|c|c|}
\hline \multirow[b]{2}{*}{$\begin{array}{l}\mathbf{N} \\
\mathbf{o}\end{array}$} & \multicolumn{4}{|c|}{ VTP Pruning Non Aktif } & \multirow[b]{2}{*}{$\begin{array}{c}\text { Kate } \\
\text { gori }\end{array}$} & \multicolumn{5}{|c|}{ VTP Pruning Aktif } \\
\hline & $\begin{array}{c}\text { Pack } \\
\text { et-1 }\end{array}$ & $\begin{array}{l}\text { Total } \\
\text { Jitter }\end{array}$ & $\begin{array}{l}\text { Rata- } \\
\text { Rata } \\
\text { Jitter }\end{array}$ & $\begin{array}{c}\text { Jitter } \\
\text { Acuan }\end{array}$ & & $\begin{array}{l}\text { Pack } \\
\text { et-1 }\end{array}$ & $\begin{array}{l}\text { Total } \\
\text { Jitter }\end{array}$ & $\begin{array}{l}\text { Rata- } \\
\text { Rata } \\
\text { Jitter }\end{array}$ & $\begin{array}{c}\text { Jitter } \\
\text { Acuan }\end{array}$ & $\begin{array}{l}\text { Kate } \\
\text { gori }\end{array}$ \\
\hline 1 & 199 & 202.162 & $\begin{array}{c}1.0158894 \\
47\end{array}$ & $\begin{array}{c}1015.88 \\
9447\end{array}$ & Jelek & 199 & $\begin{array}{c}200.76 \\
7 \\
\end{array}$ & $\begin{array}{c}1.0088793 \\
97\end{array}$ & $\begin{array}{c}1008.87 \\
9397\end{array}$ & jelek \\
\hline 2 & 199 & 202.772 & $\begin{array}{c}1.0189547 \\
74\end{array}$ & $\begin{array}{c}1018.95 \\
4774\end{array}$ & jelek & 199 & $\begin{array}{c}201.03 \\
52\end{array}$ & $\begin{array}{c}1.0102271 \\
36\end{array}$ & $\begin{array}{c}1010.22 \\
7136\end{array}$ & jelek \\
\hline 3 & 199 & 201.597 & $\begin{array}{c}1.0130502 \\
51\end{array}$ & $\begin{array}{c}1013.05 \\
0251\end{array}$ & jelek & 199 & $\begin{array}{c}201.00 \\
8 \\
\end{array}$ & $\begin{array}{c}1.0100904 \\
52 \\
\end{array}$ & $\begin{array}{c}1010.09 \\
0452\end{array}$ & jelek \\
\hline 4 & 199 & 210.233 & $\begin{array}{c}1.0564472 \\
36\end{array}$ & $\begin{array}{c}1056.44 \\
7236\end{array}$ & jelek & 199 & $\begin{array}{c}201.16 \\
14\end{array}$ & $\begin{array}{c}1.0108613 \\
07\end{array}$ & $\begin{array}{c}1010.86 \\
1307\end{array}$ & jelek \\
\hline 5 & 199 & $\begin{array}{c}205.227 \\
8 \\
\end{array}$ & $\begin{array}{c}1.0312954 \\
77\end{array}$ & $\begin{array}{c}1031.29 \\
5477\end{array}$ & jelek & 199 & $\begin{array}{c}201.21 \\
47\end{array}$ & $\begin{array}{c}1.0111291 \\
46\end{array}$ & $\begin{array}{c}1011.12 \\
9146\end{array}$ & jelek \\
\hline 6 & 199 & $\begin{array}{c}201.807 \\
1\end{array}$ & $\begin{array}{c}1.0141060 \\
3\end{array}$ & $\begin{array}{c}1014.10 \\
603\end{array}$ & jelek & 199 & $\begin{array}{c}201.70 \\
58\end{array}$ & $\begin{array}{c}1.0135969 \\
85\end{array}$ & $\begin{array}{c}1013.59 \\
6985\end{array}$ & jelek \\
\hline 7 & 199 & $\begin{array}{c}207.426 \\
773 \\
\end{array}$ & $\begin{array}{c}1.0423455 \\
93 \\
\end{array}$ & $\begin{array}{c}1042.34 \\
5593 \\
\end{array}$ & jelek & 199 & $\begin{array}{c}202.33 \\
72 \\
\end{array}$ & $\begin{array}{c}1.0167698 \\
49 \\
\end{array}$ & $\begin{array}{c}1016.76 \\
9849 \\
\end{array}$ & jelek \\
\hline 8 & 199 & $\begin{array}{c}201.955 \\
4\end{array}$ & $\begin{array}{c}1.0148512 \\
56\end{array}$ & $\begin{array}{c}1014.85 \\
1256\end{array}$ & jelek & 199 & $\begin{array}{c}204.23 \\
74\end{array}$ & $\begin{array}{c}1.0263185 \\
93\end{array}$ & $\begin{array}{c}1026.31 \\
8593\end{array}$ & jelek \\
\hline 9 & 199 & $\begin{array}{c}202.046 \\
1 \\
\end{array}$ & $\begin{array}{c}1.0153070 \\
35 \\
\end{array}$ & $\begin{array}{c}1015.30 \\
7035 \\
\end{array}$ & jelek & 199 & $\begin{array}{c}202.44 \\
06\end{array}$ & $\begin{array}{c}1.0172894 \\
47 \\
\end{array}$ & $\begin{array}{c}1017.28 \\
9447 \\
\end{array}$ & jelek \\
\hline $\begin{array}{l}1 \\
0\end{array}$ & 199 & $\begin{array}{c}201.969 \\
55 \\
\end{array}$ & $\begin{array}{c}1.0149223 \\
62\end{array}$ & $\begin{array}{c}1014.92 \\
2362 \\
\end{array}$ & jelek & 199 & $\begin{array}{c}201.51 \\
7 \\
\end{array}$ & $\begin{array}{c}1.0126482 \\
41\end{array}$ & $\begin{array}{c}1012.64 \\
8241 \\
\end{array}$ & jelek \\
\hline & $\begin{array}{l}\text { a-rata } \\
\text { itter }\end{array}$ & $\begin{array}{c}203.719 \\
6723\end{array}$ & $\begin{array}{c}1.0237169 \\
46\end{array}$ & $\begin{array}{c}1023.71 \\
6946\end{array}$ & jelek & & $\begin{array}{c}201.74 \\
243\end{array}$ & $\begin{array}{c}1.0137810 \\
55\end{array}$ & $\begin{array}{c}1013.78 \\
1055\end{array}$ & jelek \\
\hline
\end{tabular}

Berdasarkan tabel diatas, dapat diketahui hasil rekapitulasi Jitter dari skenario yang telah dilakukan, yaitu simulasi jaringan yang mengaktivkan VTP Pruning dengan yang tidak mengaktifkan VTP Pruning untuk dibandingkan hasil akhir antara keduanya. Dalam skenario simulasi dilakukan ping 100 kali dengan ukuran bytes sebesar 1000 dan proses pengambilan datanya dilakukan sebanyak 10 kali. Dalam capture data setelah simulasi dilakukan, terlihat jumlah paket data sebanyak 200. Ping dalam proses simulasi antar VLAN yang sama yaitu PC 2 ke PC 4 yang merupakan VLAN 20 dan PC 3 ke PC 1 yang merupakan VLAN 10 sebagai bentuk ping tambahan untuk melihat pengaruh VTP pruning melalui hasil parameter QOSnya dalam hal ini parameter jitter.

Hasil capture dapat disimpulkan melalui rata-rata jitter acuan akhir, dimana rata-rata jtter acuan dengan VTP pruning aktiv lebih lebih kecil nilainya dibandingkan Tanpa VTP Pruning, sehingga penggunaan VTP Pruning mempunyai pengaruh yang baik terhadap kualitas parameter jitter, walaupun kategori nilai keduanya masih termasuk kedalam kategori buruk dalam standar parameter TIPHON. Adapun jitter yang dilihat atau dilakukan proses capture merupakan dari sisi client di PC 4 VLAN 20.

Berdasarkan hasil tersebut, hasil Jitter tertinggi yaitu sebesar $1056.44 \mathrm{~ms}$, pada jaringan tanpa VTP Pruning dan Jitter terendah yaitu sebesar $1008.87 \mathrm{~ms}$ pada pada jaringan yang mengaktivkan VTP Pruning. Dapat disimpulkan nilai keseluruhan Jitter masih berkisaran $>225 \mathrm{~ms}$, dimana hasil delay ini termasuk dalam kategori buruk dalam standardisasi versi TIPHON. 


\section{Packet Loss}

Packet Loss merupakan kegagalan transmisi paket data atau dapat juga diartikan persentase hasil paket data yng tidak berhasil terkirim menuju tujuannya. Hal ini dapat terjadi akibat corupt atau terjadinya gangguan pada pengiriman. Berikut ini Hasil pengambilan data parameter packet loss yang ditampilkan pada tabel 7.

Tabel 7. Hasil Capture Packet Loss

\begin{tabular}{|c|c|c|c|c|}
\hline \multirow{2}{*}{$\begin{array}{l}\text { capture } \\
\text { ke }\end{array}$} & \multicolumn{2}{|c|}{$\begin{array}{c}\text { VTP Pruning Non } \\
\text { Aktif }\end{array}$} & \multicolumn{2}{|c|}{ VTP Pruning Aktif } \\
\hline & Paket & Packet loss & $\begin{array}{c}\text { Pake } \\
\text { t }\end{array}$ & $\begin{array}{l}\text { Packet } \\
\text { Loss }\end{array}$ \\
\hline 1 & 200 & 0 & 200 & 0 \\
\hline 2 & 200 & 0 & 200 & 0 \\
\hline 3 & 200 & 0 & 200 & 0 \\
\hline 4 & 200 & 0 & 200 & 0 \\
\hline 5 & 200 & 0 & 200 & 0 \\
\hline 6 & 200 & 0 & 200 & 0 \\
\hline 7 & 200 & 0 & 200 & 0 \\
\hline 8 & 200 & 0 & 200 & 0 \\
\hline 9 & 200 & 0 & 200 & 0 \\
\hline 10 & 200 & 0 & 200 & 0 \\
\hline \multicolumn{2}{|c|}{ rata-rata packet Loss } & $0 \%$ & & $0 \%$ \\
\hline
\end{tabular}

Berdasarkan tabel 7 diatas dapat kita ketahui nilai packet loss yang diperoleh antara skenario mengaktivkan VTP Pruning dan skenario simulasi yang tidak mengaktivkan VTP Pruning. Terlihat pada tabel bahwa nilai packet loss keduanya sama sama $0 \%$ secara rata rata. Hal ini dikarenakan selama proses pengiriman data ping tidak ada yang mengalami packet loss atau RTO (request time out). Semua data berhasil terkirim tanpa ada packet loss walau tetap mengalami delay, baik dalam skenario yang mengaktivkan VTP Pruning dan yang tidak mengaktivkan VTP Pruning. Adapun Packet Loss yang dilihat atau dilakukan proses capture merupakan dari sisi client di PC 4 VLAN 20.

Berdasarkan hasil tersebut, diketahui bahwa tidak ada packet loss terkecil maupun packet loss terbesar dikarenakan disemua skenario tidak mamiliki packet loss. Dapat disimpulkan nilai packet loss di dua skenario yaitu baik yang menggunakan VTP Pruning dengan yang tidak menggunakannya sama sama memiliki nilai rata rata packet loss yang termasuk ke dalam kategori sangat bagus dalam standar parameter jaringan menurut TIPHON.

\section{KESIMPULAN}

Kesimpulan yang diperoleh dari penelitian ini, ketika jaringan menggunakan fitur VTP Pruning maka seluruh parameter terbukti memiliki nilai yang lebih bagus jika di bandingkan dengan jaringan VLAN yang tidak mengaktivkan fitur VTP Pruning. Hal ini dapat dilihat dari nilai parameter yang dijadikan acuan penelitian. Nilai rata-rata throughput terbukti lebih baik pada jaringan yang mengaktivkan fitur VTP Pruning yaitu sebesar 2063.5 Kbps yang lebih besar dari jaringan tanpa VTP Pruning sebesar 2043.5 Kbps. Throughput terbesar juga ada pada jaringan yang menggunakan VTP Pruning yaitu sebesar 2074 Kbps sedangkan nilai throughput terkecil ada disisi jaringan yang tidak mengaktivkan VTP Pruning yaitu sebesar 1980 Kbps. Dari segi parameter Delay terlihat rata-rata delay acuan dengan VTP Pruning aktiv lebih kecil yaitu sebesar $504.84725 \mathrm{~ms}$ sedangkan yang tidak aktiv sebesar $509.8961 \mathrm{~ms}$. Delay terkecil juga ada pada sisi VTP Pruning aktiv yaitu sebesar 502.3815 ms sedangkan yang terbesar ada pada jaringan tanpa VTP Pruning sebesar $526.13 \mathrm{~ms}$. Apabila nilai parameter delay bertambah besar maka memperpanjang antrian variasi-variasi, delay pada taransmisi data pada jaringan sehingga meningkatkan nilai jitter, dengan nilai jitter tertinggi yaitu sebesar $1056.44 \mathrm{~ms}$ pada jaringan tanpa VTP Pruning dan yang terkecilnya yaitu 1008.87 ms . Rata-rata jitter acuan yaitu sebesar 1013.781055 ms saat VTP Pruning aktiv dan 1023.716946 
ms saat VTP Pruning tidak aktiv. Adapun Nilai Packet Loss sebesar $0 \%$ di kedua skenario, Baik yang menggunakan VTP Pruning maupun yang tidak menggunakannya.

\section{REFERENSI}

[1] E. V. Haryanto, Jaringan Komputer, 1st ed. Yogyakarta: Penerbit Andi, 2012.

[2] K. Nugroho, Switch dan Multilayer Switch Cisco Implementasi Jaringan Akses. Bandung: Informatika Bandung, 2017.

[3] D. Supriyadi, Andi; Gartina, "MEMILIH TOPOLOGI JARINGAN DAN HARDWARE DALAM DESAIN SEBUAH JARINGAN KOMPUTER,” Inform. Pertan., vol. 16 No 2, 2007.

[4] I. Sofana, Cisco CCNA - CCNP Routing dan Switching, BI-Obses. Bandung: Informatika Bandung, 2017.

[5] O. K. Sulaiman, "Analisis sistem keamanan jaringan dengan menggunakan Switch port Security," Comput. Eng. Syst. Sci., vol. 1 , no. 1, pp. 9-14, 2016.

[6] I. Riadi, "Optimalisasi Keamanan Jaringan Menggunakan Pemfilteran Aplikasi Berbasis Mikrotik Pendahuluan Landasan Teori,” JUSI, Univ. Ahmad Dahlan Yogyakarta, vol. 1, no. 1, pp. 71-80, 2011.

[7] R. Efendi and I. R. Widiasari, "Pengujian Kinerja Jaringan Pada Virtual Local Area Network ( VLAN ) Menggunakan Virtual Trunking Protocol ( VTP )," J. Teknol. Inf. dan Komun., vol. 3, no. 1, pp. 1-7, 2012.

[8] S. S. Hanadwiputra, “Analisa dan Implementasi VTP dengan Etherchannel Type LACP,” J. Kaji. Ilmu dan Teknol., vol. 7, pp. 2089-1245, 2018

[9] I. R. Efendi;, Rissal; Widiasari, "Segmentasi Broadcast Domain dalam Virtual Local Area Network (VLAN) dengan Memanfaatkan Virtual Trunking Protocol (VTP) Pruning untuk Penghematan Bandwidth,” J. Teknol. Inf. dan Komun., vol. 3, p. 7, 2012

[10] P. H. Sutanto, "Perancangan Virtual Local Area Network Berbasis VTP Dan Inter-Vlan Routing," J. Tek. Komput., vol. IV, no. 2 , pp. $125-134,2018$

[11] R. Wulandari, "ANALISIS QoS (QUALITY OF SERVICE) PADA JARINGAN INTERNET (STUDI KASUS : UPT LOKA UJI TEKNIK PENAMBANGAN JAMPANG KULON - LIPI),” J. Tek. Inform. dan Sist. Inf., vol. 2, no. 2, pp. 162172, 2016.

[12] W. P. Sasmita, N. Safriadi, and M. A. Irwansyah, "Analisis Quality of Service (QoS) pada Jaringan Internet (Studi Kasus: Fakultas Kedokteran Universitas Tanjungpura)," J. Sist. dan Teknol. Inf., vol. 1, no. 1, pp. 37-43, 2013.

[13] TIPHON, "Telecommunications and Internet Protocol Harmonization Over Networks (TIPHON); General aspects of Quality of Service (QoS)," 1999. 